Anthologies and Miscel-

lanies. Access: hitp:

humanitas.ucsb.edu/ depts/english/research/ $\mathrm{grad} / \mathrm{anthologies}$

This authoritative site should be of interest to faculty and upper-division students studying English poetry and the history of literary canons. Based on the authors' researches at the British Library, this site presents tables of contents, some prefatory and introductory material, and occasionally the authors notes from almost 100 anthologies, miscellanies, and beauties collections of English poetry from the 18 th to the 20 th century. Authors Laura Mandell, assistant professor of English at Miami University of Ohio, and Rita Raley, English cloctoral student at the University of California at Santa Barbara, both researchers of canon formation and the history of the anthology form, write in the introduction. "This site aims to provide a historical and theoretical context for the stillcontested canon of English poetry."

The main page begins with a discussion of the site's purpose. This is followed by the poetry collections themselves, identified by editor, title, and date. and grouped in chronological order within the categories "Anthologies," "Collections Larger than 6 Volumes," "Mid 18th Century Miscellanies: The Dodsley Group," "Miscellanies: Beauties," and "20th Century Anthologies." The titles act as links to the tables of contents, which the authors have attempted

\section{Anthologies and Miscellanies}

to reproduce as faithfully as possible. Other links make it possible to view the collections chronologically or alphabetically by editor; another subpage lists those collections designed for use in the schools.

This site should prove a unique source of both raw material and theoretical background. As the authors discuss in the introduction, the data allow users to see how individual poets have been received by the reading public over the centuries and how each era shapes the notions of period, canon, and "major" and "minor" writers, and can provicle a basis for any number of comparative studies. Included are links to other sites by the authorsfor example, Laura Manclell's Romantic Canons: A Bibliography (and an Argument)which develop the theoretical framework and provide references for further study. The authors intend to expand the historical parameters of the site with links to subpages based on related topics, and to increase its representation of earlier collections as well as its representation of 20th-century collections. This site is linked to the collective Web resource, Romantic Circles (http://www.inform.umd.edu/ $\mathrm{RC} / \mathrm{rc} \cdot \mathrm{html}$ ).

Anthologies and Miscellanies is clearly laid out and straightforward in use. The basic introductory material and all of the title lists are provided on the main page. This makes the main page quite long but does not create any significant delays in browsing the content. The authors intend to provide a search engine in the near future, a welcome addition as this will allow the data to be manipulated in ways specifically useful to the researcher.-Joseph $A$. LaRose, University of Akron; jl@uakron.edu

Statistics Canada. Access: http://www. statcan.ca.

Statistics Canada is both Canada's national statistical agency and the name of its government-run Web site. Its mission is to "collect, compile, analyse, abstract, and publish statistical information of virtually every aspect of the nation's society and economy." Statistics Canada comes in both English and French versions, the homepage giving you your choice of language. After choosing one, the welcome screen gives you many more choices, including 1)aily News, the 1996 Census, the location of its Service Centres, and basic Canadian statistics on the economy, land, people, and government. Navigation tools include both a search engine and a site map.

One of the major features of the site is a page updated daily, called, appropriately, the daily. The Daily is an electronic version of Sta-

Sara Amato is automated systems librarian at Central WasbingtonUniuenity: samato@taboma.cu'u.edu 
content by creating a Web site rich with primary material, as well as bibliographies and other research guides. Lycos gives the center a score of 78 , out of a possible 100 ,

tistics Canada's official release bulletin, first published in 1932. The Daily consists of both statistical data highlights and lists of recently published documents. For example, the one I viewed had reports on the earning characteristics of "two-partner families" and estimates of principal field crop production. A catalog number was also given so that you may order the document (for a fee), either online or by mail. Other publications may be ordered (again, for a fee) in either Adobe Acrobat format or in paper.

The search engine offered by Statistics Canada may be used to explore the entire Web site or selected databases, such as the Daily, Information on Products and Services (IPS) catalog, Research Papers and more. I tried a search in the Research Papers, section on "grizzlies," "bears," and then finally "wildlife." I retrieved zero results on "bears" and "grizzlies." "Wildlife," however, gave me a listing of 14 ranked results, one of which was a table listing the prairie population of grizzlies as being extinct. This came up only because the source of the clocument was the Canadian Wildlife Service.

Statistics Canada uses the Excite for Wel) Servers as its search engine. This search engine claims to "search for documents that are a best match for the words in your query." For narrowing your results you "simply use more words in your query," the opposite of what we boolean searchers have been taught. You can still use boolean operators, however, to formulate a query.

Statistics Canada is an extremely vital source of Canadian information and should always be considered by those looking for both current and archived governmental statistical reports. Its Daily page makes it not just a repository for government documents but a current source of information to anyone interested in Canada's land, economy, and people.-Fim Rible, Southem Oregon University; rible@son.edu

Naval Historical Center. Access: http:/ www. history navy.mil.

Content is the essential element of any Web resource. The staff of the Naval Historical Center has done an outstanding job of providing for content. From the viewpoint of a librarian (and navy veteran), the score should be higher.

The site is organized in an easily navigable hierarchy, with the "Welcome Aboard" homepage laying out the resources of the site. Going deeper, one finds the text of "A History of the U.S. Navy," from Encyclopedia of the American Military. The center provides an index of operational archives, links to the homepages of historical ships such as the USS Constellation, and the digitized version of Naval Aviation News, the navy's oldest periodical. The bimonthly journal is presented in Portable Document Format (PDF), and holdings start with November-December 1996. There is a "frequently asked questions" (FAQ) section covering such topics as Amelia Earhart, Lieutenant George Bush, and the disappearance of Flight 19. The site also provides plenty of trivia, such as navy recipes.

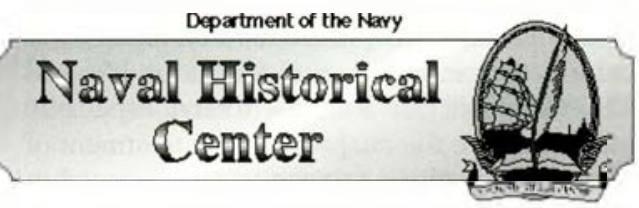

One surprising part of the site is the subject of underwater archaeology. The center conducts ongoing research into navy wrecks, such as that of the CSS Alabama. Other unexpected pleasures include images from the Navy Art Gallery and a link to the online cattalog of the 200,000-volume Navy Department Library.

Researchers will probably find the detailed master bibliography the most useful section of the site. The bibliography was created with distant users in mind: most of the 450 books can be found in college or university libraries. It is broken down into such subheadings as "Expeditions and Exploration" and "Quasi-War with France and Barbary Wars." Scholars will also be interested in the center's fellowships and grants, the requirements of which are given.

The center has created a content-rich, friendly resource that deserves to be bookmarked not only by navy buffs but by anyone with an interest in U.S. history.-Wes Edens, University of North Dakota; edens@badlands. nodak.edu. 